\title{
O Jogo do Sim ou Não: uma ferramenta educacional no ensino de Química, em especial, de nomenclatura dos compostos orgânicos
}

Gean Carlos de Sousa*(Graduando em Ciência e Tecnologia na Universidade Federal Rural do Semi-Árido -

UFERSA, campus Mossoró-RN);

Carlos Antônio Barros e Silva Júnior (Professor no Instituto Federal de Educação, Ciência e Tecnologia do Rio

Grande do Norte - IFRN, campus Ipanguaçu-RN);

Cinthya Raquel da Costa Silva (Graduanda em Ciência e Tecnologia na Universidade Federal Rural do Semi-

Árido - UFERSA, campus Mossoró-RN);

Airlis Mendes de Freitas Júnior (Graduando em Ciência e Tecnologia na Universidade Federal Rural do Semi-

Árido - UFERSA, campus Mossoró-RN);

Aline Beatriz de Medeiros (Graduando em Ciência e Tecnologia na Universidade Federal Rural do Semi-Árido -

UFERSA, campus Mossoró-RN)

*Email:geancsousa@gmail.com

resumo:

Existem muitas dificuldades apresentadas pelos alunos no que diz respeito ao entendimento nos assuntos de Química, estas dificuldades devem-se, muitas vezes, a falta de interesse e motivação, que unidas à metodologia dos professores, não permitem que o aluno consiga concretizar dado conhecimento. Este trabalho tem como objetivo mostrar a aplicação de um jogo que foi utilizado como mecanismo pedagógico para facilitar o ensino de Química, em particular, de nomenclatura dos compostos orgânicos, bem como os resultados de sua aplicação. São discutidas as etapas de aplicação e avaliação da proposta "Jogo do Sim ou Não". O jogo foi aplicado nos alunos das turmas de terceiro ano do Ensino Médio, na Escola Estadual do município de Icapuí-CE. A avaliação dos dados obtidos, com relação às notas dos alunos, mostra uma evolução considerável do desempenho. A receptividade dos alunos a essa proposta pedagógica foi satisfatória, pois logo após o início do jogo todos já se mostraram envolvidos. Dessa forma, pode-se afirmar que a proposta pode ser aplicada em outras instituições de ensino, de modo a motivar os alunos no processo de ensino-aprendizagem.

palavras-chave:

Interesse; Motivação; Ensino de Química; J ogo; Processo de ensino-aprendizagem.

Espaço reservado para organização do congresso. 


\section{I NTRODUÇÃO}

A Química é uma ciência fundamental para o desenvolvimento da sociedade. Ela é a chave para a explicação de vários fenômenos recorrentes no nosso cotidiano, por esse motivo é uma disciplina imprescindível no currículo do Ensino Básico e deve ser discutida em sala de aula levando-se em consideração não só as dimensões científicas, como também as sociais e culturais.

Todavia, observa-se na rotina da maioria das aulas desta disciplina, a falta de interesse por parte dos alunos, que muitas vezes está vinculada as dificuldades encontradas por estes na assimilação de assuntos específicos. Cardoso e Colinvaux (2000) afirmam que estudantes do ensino médio geralmente demonstram dificuldades para assimilar alguns conceitos científicos nas disciplinas que compõem as ciências exatas como a Química. Já Gibin e Ferreira (2010) afirmam que os alunos do Ensino Médio têm dificuldades para aprender Química e geralmente não conseguem estabelecer relações apropriadas entre os níveis macroscópico, simbólico e o submicroscópico.

Sobre isso Nunes e Adorni (2010) afirmam que no ensino da Química, observam-se alunos que muitas vezes não conseguem aprender e não são capazes de associar o conteúdo estudado com seu cotidiano, por isso perdem o interesse. Desta forma percebe-se que muitas vezes o ensino desta disciplina está sendo feito de forma descontextualizada e não interdisciplinar.

Com relação a esse assunto, Trevisan e Martins (2006) afirmam que é necessário falar em educação química, levando-se em consideração a sua contextualização com os fenômenos e acontecimentos do cotidiano do aluno, para que estes percebam sua importância socioeconômica, numa sociedade avançada, tanto no sentido tecnológico quanto no sentido social.

Diante das dificuldades encontradas no ensino de Química percebe-se que é necessário se trabalhar com novas possibilidades, estratégias ou propostas pedagógicas facilitadoras que possam proporcionar o estreitamento da relação ensino-aprendizagem nesta disciplina. Segundo Moreira (2006), a elaboração de um material didático que seja potencialmente significativo, pode proporcionar no aluno uma motivação para estudar e aprender Química, porém esse material deve ser elaborado de uma forma que permita a integração entre o conhecimento prévio do aluno e a nova informação apresentada pelo professor.

Uma alternativa pedagógica para sanar essas dificuldades no ensino desta disciplina é a utilização do lúdico. Benedetti Filho et al. (2009) afirma que o lúdico, quando utilizado no ensino de conceitos em sala de aula, torna-se uma ferramenta que atrai o interesse dos alunos, ou seja, uma motivação na busca de respostas para as atividades propostas. A falta de interesse por parte do estudante deve ser analisada, de forma especial pelo docente que preza pelo aprendizado de seus alunos. Segundo Cavalcanti, Deus e Soares (2007), o jogo se torna um instrumento de instiga o interesse do estudante, pois impõem a ele um desafio. Quando desafiado, busca, com satisfação, alcançar seus objetivos, superando obstáculos, devido ao fato do interesse preceder a assimilação.

Robaina (2008) argumenta que a utilização dos jogos pedagógicos é uma alternativa viável e promissora, já que podem ser confeccionados com materiais que fazem parte do ambiente de sala de aula ou que são descartados nas residências. É justamente essa a ideia da aplicação do lúdico em sala de aula, a de levar em consideração tanto a facilidade de assimilação do conteúdo, quanto à confecção dos jogos, pois isso contribui para que os alunos se utilizem da sua criatividade e se tornem construtores do próprio conhecimento, desenvolvendo inclusive seus próprios jogos. Para ratificar essa ideia, Nardin (2008) afirma que a implantação do jogo, produz um ambiente de interação e criatividade, proporcionando o aprendizado almejado, com sentido e significado, onde gostar e querer se fazem presentes.

A respeito dos jogos químicos, Soares (2004) acredita na possibilidade de despertar o interesse do discente para o ensino de química, produzindo-se jogos que busquem representar os eventos microscópicos e abstratos de forma macroscópica e palpável. Os jogos, segundo Cunha (2012) podem e devem ser utilizados como recursos didáticos na aprendizagem de conceitos em sala de aula, de forma a auxiliar na aprendizagem dos estudantes, sendo um recurso facilitador na obtenção da informação por estes.

Essa dificuldade que os alunos encontram para aprender alguns assuntos de Química é preocupante, por isso é necessário que os professores se utilizem de algum recurso inovador que possa suprir essa dificuldade. Um dos assuntos que os estudantes encontram mais dificuldades é o que está 
relacionado à nomenclatura dos compostos orgânicos, pois este assunto envolve um número consideravelmente elevado de informações.

Este trabalho objetiva mostrar a aplicação um jogo que foi utilizado como mecanismo pedagógico para facilitar o ensino de nomenclatura dos compostos orgânicos, bem como os resultados de sua aplicação. Neste artigo será mostrada a aplicação deste jogo apenas para o assunto de hidrocarbonetos, muito embora possa também ser aplicado para o entendimento de nomenclatura dos compostos orgânicos oxigenados e nitrogenados.

\section{METODOLOGIA}

O Jogo do Sim ou Não pode ser utilizado em sala de aula como uma ferramenta pedagógica alternativa que pode contribuir para o entendimento dos assuntos relacionados à nomenclatura dos compostos orgânicos, principalmente os hidrocarbonetos e os compostos oxigenados e nitrogenados. A finalidade do Jogo do Sim ou Não neste trabalho é fazer com que os alunos consigam identificar, com precisão, todas as classes dos hidrocarbonetos tais como: alcanos, alcenos, alcinos e outras. Este também pode ser utilizado para auxiliar na compreensão de compostos oxigenados (álcoois, aldeídos, cetonas e outros) e nitrogenados como as aminas, amidas, nitrilas e etc.

O jogo é uma competição entre os grupos da sala de aula que são previamente divididos. Com o objetivo de desvendar o nome de uma estrutura orgânica que o professor escolheu e em seguida guardou de forma sigilosa para que os alunos não visualizassem. Essa estrutura poder ser um hidrocarboneto, um composto oxigenado ou nitrogenado, ficando a critério do professor essa escolha.

O professor além de intermediador também é participante do jogo. Os grupos deverão elaborar perguntas que serão feitas a ele, de modo que este só poderá responder "sim ou não" (por isso que o jogo recebe este nome). As perguntas precisam ser bem elaboradas, pois do contrário, o professor não poderá respondê-las. Se, por exemplo, o grupo fizer a seguinte pergunta: "Qual o número de carbonos que este composto (escondido) apresenta na cadeia principal?”, com certeza este grupo não obterá resposta, pois não tem como o professor responder sim ou não. Por outro lado, se esta equipe perguntar: "Neste composto, o número de carbonos na cadeia principal é igual a seis?”, a pergunta possibilitará uma resposta pautada entre o binômio sim ou não. O material didático disposto pelos alunos, como livro, caderno, apostila, podem ser utilizados pelas equipes, para que possam elaborar as perguntas e tentar descobrir as respostas. Estas perguntas objetivam obter informações a respeito da estrutura escolhida pelo professor. Em cada rodada de perguntas as equipes descartam as possibilidades e se aproximam mais da nomenclatura correta.

Este jogo foi aplicado em três turmas de terceiros anos $\left(3^{\circ} \mathrm{A}, 3^{\circ} \mathrm{B}\right.$ e $\left.3^{\circ} \mathrm{C}\right)$ do Ensino Médio numa Escola Estadual no município de Icapuí-CE. Inicialmente foram ministradas seis aulas teóricas referentes ao assunto de hidrocarbonetos, nas quais foram trabalhadas as estruturas e nomenclaturas de todas as subclasses de hidrocarbonetos. Mediante as dificuldades encontradas pelos estudantes na resolução dos exercícios sobre este conteúdo, foi realizado em duas aulas o jogo intitulado por "jogo do sim ou não". Porém antes da aplicação deste foi feita uma avaliação diagnóstica com apenas duas questões relacionadas à estrutura e nomenclatura dos hidrocarbonetos. Esta avaliação, intitulada por “avaliação pré-jogo" foi utilizada posteriormente para se fazer uma análise comparativa com outra avaliação (com o mesmo nível e formato que a anterior) realizada depois da aplicação do jogo.

Para a realização deste jogo, a sala de aula foi dividida em cinco grupos de seis alunos, pois as turmas da escola continham, em média, trinta estudantes. O jogo começou com o professor desenhando uma estrutura de um hidrocarboneto, com sua respectiva nomenclatura, em um pedaço de papel que foi depois guardado em uma caixa de papelão, isto para que nenhum aluno tivesse contato com a resposta. As equipes precisavam se organizar de forma que não pudessem entrar em contato umas com as outras. Os grupos foram numerados de um a seis.

O jogo foi iniciado nas duas primeiras aulas e terminado nas aulas seguintes, levando em consideração a pontuação das equipes nas aulas anteriores e acumulando com os pontos obtidos nas aulas seguintes. No encontro posterior, foi aplicada, a avaliação intitulada por "avaliação pós-jogo".

\subsection{Regras do J ogo}


- Para o início do jogo, é necessário separar a turma em grupos, sendo que para cada grupo é escolhido uma numeração. Após esse processo, é feito um sorteio da equipe que irá iniciar o jogo;

- Cada equipe só tem direito a uma pergunta por rodada. Todavia, se a equipe após a resposta do professor conseguir obter uma resposta para a nomenclatura da substância desconhecida, terá o direito de arriscar a resposta sem necessidade de esperar uma nova rodada ser iniciada;

- Se a resposta da equipe estiver errada, ela não é penalizada com perda de pontuação, apenas passará a vez para o próximo grupo;

- Se alguma equipe já conseguir a resposta, deverá esperar sua oportunidade de responder;

- A equipe que acertar a resposta ganhará um ponto e quando isso ocorrer, o professor elabora outra estrutura e o jogo recomeça com o grupo com numeração seguinte ao que iniciou anteriormente; Vence o jogo a equipe que acumular o maior número de pontos, ou seja, a que acertar o maior número de nomenclaturas.

\section{RESULTADOS E DISCUSSÃO}

Antes da aplicação do jogo, na escola analisada, os alunos apresentavam muitas dificuldades no entendimento do assunto, principalmente no que se diz respeito ao entendimento das nomenclaturas das classes dos hidrocarbonetos, bem como suas respectivas estruturas. Isto foi comprovado após resultado da avaliação pré-jogo que mostrou que alguns alunos não aprenderam nem mesmo identificar essas classes.

Ao ser iniciado o jogo, percebeu-se que nem todos os alunos dos grupos se envolviam, porém, com o decorrer do tempo e com o aumento da disputa entre as equipes, observou-se que quase todos os alunos encontravam-se participantes. O envolvimento era tão grande por parte dos alunos que estes não queriam parar de jogar.

Esse jogo provocou uma motivação maior, nos alunos, e a aula tornou-se dinâmica, pois permite que todos participem de uma competição instigante. Essa "atmosfera" de competição desperta nos alunos uma vontade de aprender mais sobre os assuntos relacionados às nomenclaturas dos compostos orgânicos, visto que o desejo de grande parte deles é de ser vencedor da competição. No decorrer do jogo já se percebia a evolução de alguns alunos que conseguiam diferenciar facilmente as famílias dos hidrocarbonetos. Depois da realização do jogo, os alunos apresentavam uma grande evolução no entendimento da aplicação dos prefixos e radicais utilizados na montagem das nomenclaturas dos compostos orgânicos.

$\mathrm{Na}$ aplicação da avaliação "pós-jogo", percebeu-se que os alunos demonstravam uma facilidade maior no entendimento das questões, sendo que alguns argumentavam que esta avaliação estava mais fácil que a avaliação pré-jogo. Os resultados das duas avaliações aplicadas nas escolas estão nos Gráficos 1, 2, e 3 onde se pode perceber a relação entre as duas notas de cada aluno, por consequência disso foi possível avaliar a eficiência da aplicação do jogo.

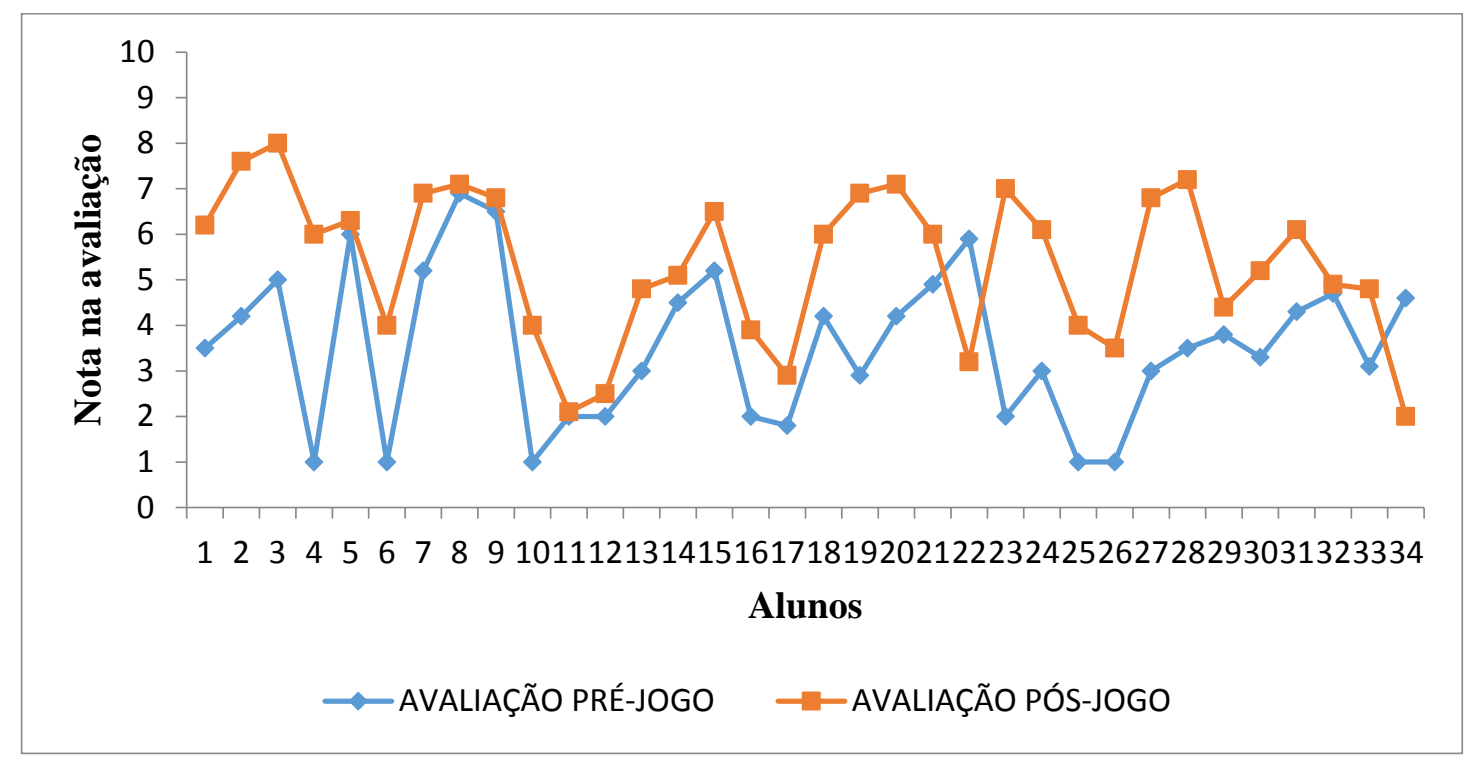


Gráfico 1 - Resultados dos alunos da turma do $3^{\circ}$ A nas avaliações pré-jogo e pós-jogo.

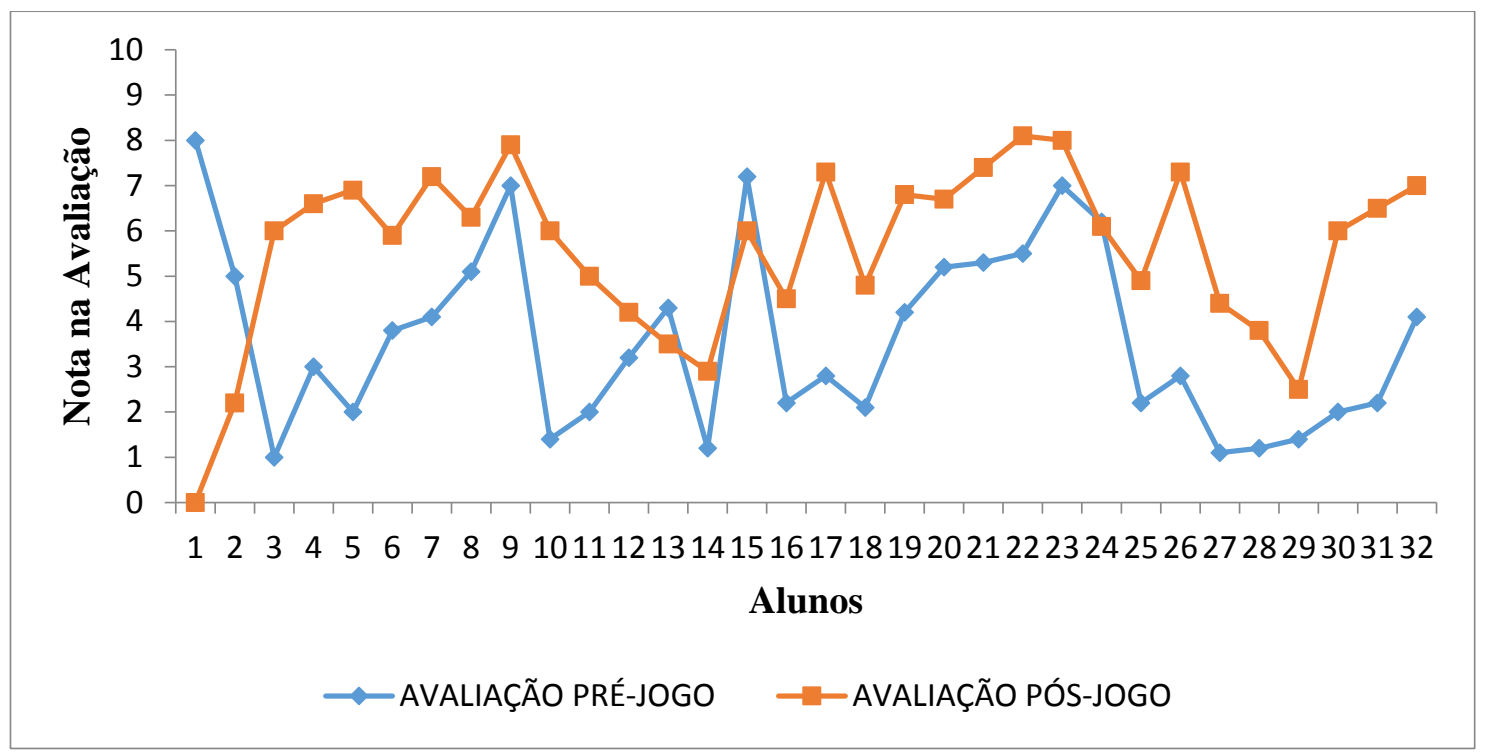

Gráfico 2 - Resultados dos alunos da turma do $3^{\circ} \mathrm{B}$ nas avaliações pré-jogo e pós-jogo.

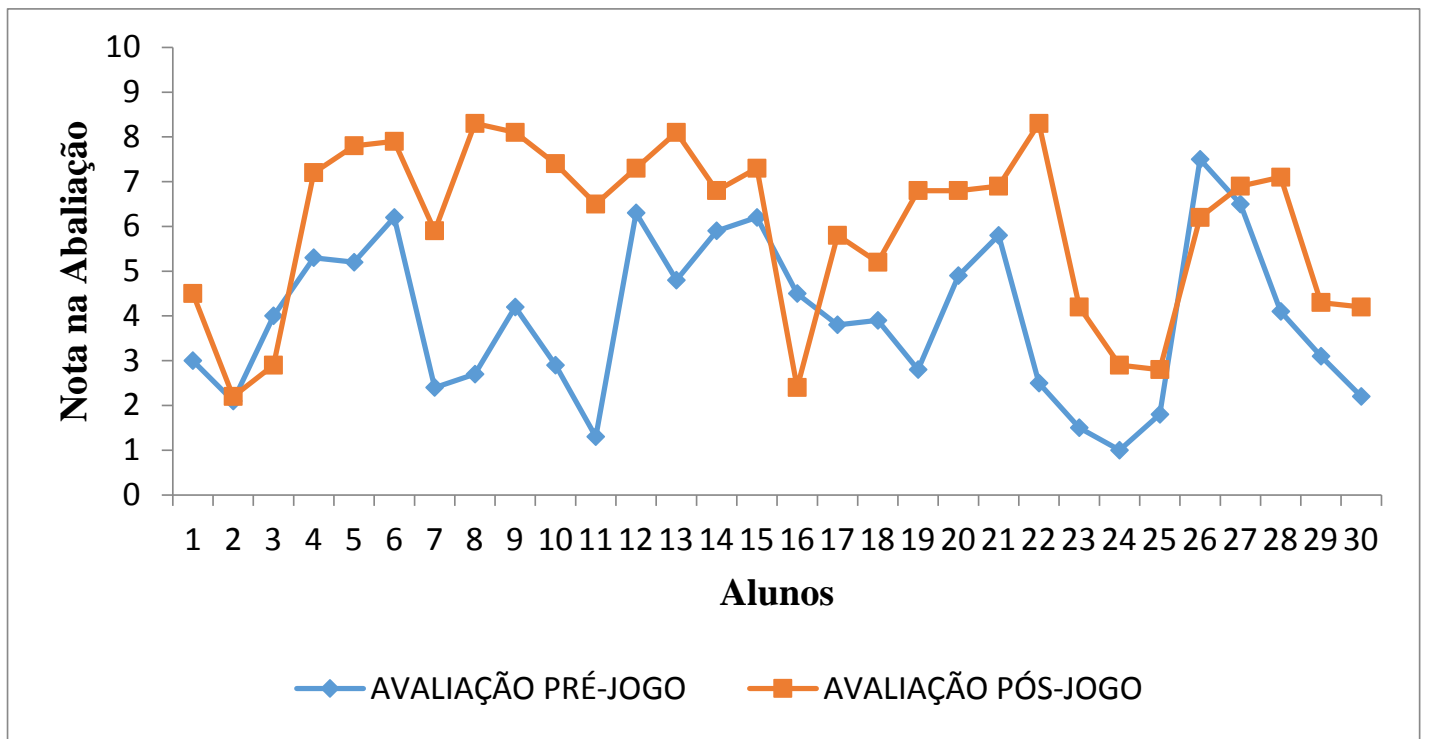

Gráfico 3 - Resultados dos alunos da turma do $3^{\circ} \mathrm{C}$ nas avaliações pré-jogo e pós-jogo.

Analisando os resultados comparativos das avaliações aplicadas nas três turmas, antes e depois do jogo, observa-se que houve uma evolução significativa nas notas da maioria dos alunos. Por mais que alguns estudantes não tenham melhorado seu desempenho, ficando alguns com notas mais baixas depois da aplicação do jogo, nota-se que a aplicação deste foi determinante para que houvesse essa elevação nas notas da maioria dos alunos.

Uma observação a ser feita está ligada ao baixo desempenho de alguns alunos da escola, que mesmo com a aplicação do jogo, não conseguiram apresentar resultados satisfatórios. A isso se pode creditar à motivação apenas ao jogo em si, interessando para esses alunos apenas a vitória e não o entendimento dos assuntos ligados ao jogo.

\section{CONSI DERAÇÕES FINAIS}

Diante dos resultados alcançados pela aplicação do "jogo do sim ou não", entende-se que o emprego de jogos como recurso pedagógico nas aulas de química pode ser uma alternativa para que estas se 
tornem mais prazerosas e efetivas, visto que neste caso, foi observada uma grande motivação e envolvimento dos alunos nas aulas que envolveram a aplicação do jogo.

No que concerne ao entendimento dos conteúdos, pode-se afirmar, com base nos resultados obtidos, que o jogo foi fundamental para que os alunos conseguissem entender, diferenciar e tratar da nomenclatura dos hidrocarbonetos. Antes do jogo os alunos não conseguiam saber diferenciar nem mesmo um hidrocarboneto dos demais e nem fazer a nomenclatura de uma determinada estrutura. Por outro lado, depois que o jogo foi trabalhado em sala, os alunos já conseguiam facilmente identificar os hidrocarbonetos e suas respectivas nomenclaturas.

Com relação à aplicação deste jogo pode-se ressaltar sua relevância para aplicações futuras, também por outros professores, visto que foi alcançado êxito com sua aplicação. Vale ressaltar que o jogo por si só não sanará as dificuldades dos alunos em determinado conteúdo. É necessário que haja um planejamento efetivo que leve em consideração os verdadeiros objetivos que devem ser alcançados, sem esquecer-se das possíveis dificuldades que poderão ser encontradas, do contrário a aula perderá seu sentido didático-pedagógico.

\section{The Game Yes or Not: an educational tool in chemical teaching in particular for naming organic compounds}

Albstract: There are many difficulties presented by students with regard to understanding the chemistry issue, these difficulties are often the lack of interest and motivation, which joined the methodology of teachers, do not allow the learner to realize notified. This work aims to show the application of a game that was used as a pedagogical mechanism to facilitate the teaching of Chemistry in particular naming of organic compounds, as well as the results of your application. The application steps and evaluation of the proposal are discussed "the game Yes or Not". The game was applied to the students of the third year of high school classes at the state school in the city of IcapuíCE. The evaluation of the data obtained, with respect to students' grades, shows a considerable evolution of performance. The receptivity of students to this pedagogical proposal was satisfactory, since shortly after the beginning of the game all have proven involved. Thus, it can be said that the proposal can be applied to other educational institutions, so as to motivate students in the teachinglearning process.

Keywords: Interest; motivation; Chemistry education; game; Teaching-learning process.

\section{Referências bibliográficas}

BENEDETTI FILHO, E.; FLORUCCI, A.R.; BENEDETTI, L.S.; CRAVEIRO, J.A. Palavras cruzadas como recurso didático no ensino da Teoria Atômica. Revista Química Nova na Escola, São Paulo-SP, v. 3, n. 2, p. 88-95, Maio/2009.

CARDOSO, S. P.; COLINVAUX, D. Explorando a motivação para estudar química. Revista Química Nova na Escola, São Paulo, v. 23, n.3, p. 401-404, 2000.

CAVALCANTI, E.L.D.; DEUS, T.C. e SOARES, M.H.F.B. Perfil químico: um jogo didático para promover a interação e o conhecimento. In: Anais. 30a Reunião Anual da Sociedade Brasileira de Química, 2007. Disponível em: < http://sec.sbq.org.br/cdrom/30ra/resumos/T0565-1.pdf >. Acesso em 01 de J ulho de 2015. 
CUNHA, M. B. Jogos no Ensino de Química: Considerações Teóricas para sua Utilização em Sala de Aula. Revista Química Nova na Escola, São Paulo-SP, v. 34, n. 2, p.92-98, Maio/2012.

GIBIN, G. B.; FERREIRA, L. H.. A formação inicial em química baseada em conceitos representados por meio de modelos mentais. Revista Química Nova na Escola, São Paulo, v. 33, n. 8, p. 1809$1814,2010$.

MOREIRA, M.A. (2006). A teoria da aprendizagem significativa e sua implementação em sala de aula. Brasília: Universidade de Brasília, 186 p.

NARDIN, I. C. B. Brincando aprende-se química. Disponível em: < www. diaadiaeducacao.pr.gov. br/portals/pde/arquivos/688-4. pdf>. Acesso em 16 de Julho de 2015.

NUNES, A. S.; ADORNI, D.S . O ensino de química nas escolas da rede pública de ensino fundamental e médio do município de Itapetinga-BA: O olhar dos alunos. In: Encontro Dialógico Transdisciplinar - Enditrans, 2010, Vitória da Conquista, BA. - Educação e conhecimento científico, 2010.

ROBAINA, J. V. L. Química através do lúdico: brincando e aprendendo. Canoas: Ed. Ulbra, 2008, 480p.

SOARES, M.H.F.B. O lúdico em química: jogos e atividades aplicados ao ensino de química. 2004. 203f. Tese (Doutorado em Ciências) - Centro de Ciências Exatas e de Tecnologia, Universidade Federal de São Carlos, São Carlos-SP, 2004.

TREVISAN, Tatiana Santini; MARTINS, Pura Lúcia Oliver. A prática pedagógica do professor de química: possibilidades e limites. UNI revista, v. 1, n. 2, Abril/2006. 